\title{
Dynamic thinning of Antarctic glaciers from along-track repeat radar altimetry
}

\author{
Thomas FLAMENT, Frédérique RÉMY \\ Laboratoire d'Etudes en Géophysique et Océanographie Spatiale (Legos), Toulouse, France \\ E-mail: thomas.flament@legos.obs-mip.fr
}

\begin{abstract}
Since 2002, the Envisat radar altimeter has measured the elevation of the Antarctic ice sheet with a repeat cycle of 35 days. This long and regular time series is processed using an along-track algorithm to depict in detail the spatial and temporal pattern of elevation change for the whole ice sheet. We use this dataset to examine the spatial and temporal pattern of Pine Island Glacier (PIG) thinning and compare it to the neighbouring glaciers. We also examine additional areas, especially in East Antarctica whose mass balance is poorly known. One advantage of the finer along-track spacing of measurements is that it reveals places of dynamic thinning in regions of rapid ice flow. We observe the acceleration of thinning on PIG. Over the entire basin, the volume loss increased from $7 \mathrm{~km}^{3} \mathrm{a}^{-1}$ during 2002-06 to $\sim 48 \mathrm{~km}^{3} \mathrm{a}^{-1}$ during 2006-10. We also observe accelerated thinning on the lower tens of kilometres of Thwaites Glacier, with a mean thinning of $0.18 \mathrm{~m} \mathrm{a}^{-1}$ over its entire basin during our observation period. We confirm the dynamic thinning of Totten Glacier but we do not detect significantly accelerated thinning on any glacier elsewhere than on the coast of the Amundsen Sea.
\end{abstract}

\section{INTRODUCTION}

The mass balance of an ice sheet can be estimated by several different techniques, one of which is altimetry (e.g. Allison and others, 2009). Repeated elevation measurements at the same locations provide volume variations that can be converted to mass variations by adding an assumption on the associated density.

In several locations around Antarctica, changes in mass balance linked to changes in the ice flow ('dynamic changes') have been identified (e.g. Pritchard and others, 2009). For instance, glaciers flowing into the former Larsen $B$ ice shelf accelerated immediately after the disintegration of the ice shelf in 2002. This increase in ice flow velocity caused rapid thinning because of faster drainage of ice (Shuman and others, 2011). However, the surface height evolution of these glaciers cannot be studied properly with classical radar altimetry because of the relief surrounding them.

Pine Island Glacier (PIG), by contrast, is much more easily observable, because of its large drainage basin and high thinning rates. It has been identified as being massively out of balance since the 1990s (Shepherd and others, 2001). Accumulation over its basin totals a little over $60 \mathrm{Gt} \mathrm{a}^{-1}$, but the glacier discharged $77 \mathrm{Gta}^{-1}$ of ice in 1996 (Rignot and others, 2004), $85 \mathrm{Gta}^{-1}$ in 2000 (Rignot, 2008, table S1) and $103 \mathrm{Gta}^{-1}$ in 2006 ( $+34 \%$ compared with 1996; Rignot, 2008). The onset of this large out-of-balance discharge is thought to have been provoked by ocean warming that thinned the ice shelf and ice plain (Corr and others, 2001), leading to the ungrounding of this plain (Thomas and others 2004; Jenkins and others, 2010). With the help of European Remote-sensing Satellite (ERS-2) and Envisat radar altimetry, Wingham and others (2009) observed accelerated thinning near the grounding line. Other glaciers in the vicinity are exposed to the same conditions, namely Thwaites, Pope, Smith and Kohler glaciers. The latter three were reported to be accelerating, whereas the Thwaites Glacier region of fast flow seems to be widening (Rignot, 2008).
Dynamic thinning of the ice sheets could play a prominent part in global sea level in the next century. It is therefore necessary to better understand this phenomenon.

The aim of this paper is to complete and extend the temporal series with the whole Envisat 35 day repeat orbit that started in austral spring 2002 (with valid data from September 2002) and ended in November 2010. To make the most of this dataset, we introduce an along-track processing that produces much denser coverage than the usual crossover processing. The sampling is also more regular in time, and the series longer, than can be obtained from 2003-09 Ice, Cloud and land Elevation Satellite (ICESat) data acquired during two to three campaigns each year between 2003 and 2009 (see Pritchard and others, 2009 who used 2003-07 ICESat data).

We first focus on PIG, taking advantage of previous work and of in situ measurements to validate our processing scheme. Then we examine whether dynamic thinning can also unambiguously be detected on other locations of the Antarctic ice sheet (AIS).

\section{DATA AND METHODS}

\subsection{Along-track processing}

The along-track processing used in this study is largely inspired by the work of Legrésy and others (2006) but it is also similar to the method used by Zwally and others (2011) or method M3 of Sørensen and others (2011) (see also Howat and others, 2008; Smith and others, 2009). Unlike the usual crossover analysis that uses only data points where satellite tracks cross, this method considers all the altimeter measurements, i.e. one point every $350 \mathrm{~m}$ along-track. The result is a large increase (by a factor 25 ) in the number of available data points (from 60000 crossovers to $>1500000$ along-track processed points for the whole AIS). Moreover, the tracker system can lose lock when the satellite is flying from the ocean towards steep terrain so that some coastal crossovers are missing whereas one track is available. Alongtrack processing is thus of particular interest near the 
Antarctic coast, at lower latitudes, where the dynamic signal is assumed to be strong and data coverage is sparse.

Each satellite track was flown over up to 83 times during the study period (September 2002 to October 2010, cycles 9-94, the ' 35 day repeat Envisat period'). Here we chose to compute the elevation trend every kilometre along-track. All available measurements within a $500 \mathrm{~m}$ radius of a point on the mean ground track were selected and processed together. The $500 \mathrm{~m}$ radius is appropriate for two reasons. First, it corresponds to the across-track scatter of the points flown over by the satellite, as provided by orbit control. Second, it is possible to model the topography at this scale using a simple quadratic form (of the along- and across-track coordinates). Using the quadratic form we obtain elevation residuals with a root mean square $(\mathrm{rms})$ of $40 \mathrm{~cm}$, whereas with a simple linear fit the rms was $46 \mathrm{~cm}$. Using the quadratic form instead of a plane thus provides a gain of $22 \mathrm{~cm}$ rms.

The processing includes corrections based on waveform parameters (computed by the ICE-2 retracker (Legrésy and others, 2005)) to account for varying electromagnetic properties of the ice-sheet surface. The overall processing in itself is a least-square fit to the measured elevations (Rémy and Parouty, 2009).

The least-square model can be written:

$$
\begin{aligned}
H(x, y, t)= & \mathrm{dBS}(\mathrm{bs}-\overline{\mathrm{bs}})+\mathrm{dLEW}(\mathrm{lew}-\overline{\mathrm{lew}}) \\
& +\mathrm{dTES}(\mathrm{tes}-\overline{\mathrm{tes}}) \\
& +H_{0}(\bar{x}, \bar{y})+\mathrm{s} x(x-\bar{x})+\mathrm{s} y(y-\bar{y}) \\
& +\mathrm{c} x\left(x^{2}-\overline{x^{2}}\right)+\mathrm{c} y\left(y^{2}-\overline{y^{2}}\right) \\
& +\mathrm{c} x y\left(x^{2}-\overline{x^{2}}\right)\left(y^{2}-\overline{y^{2}}\right) \\
& +\mathrm{d} h / \mathrm{d} t(t-\bar{t}) \\
& +\operatorname{res}(x, y, t)
\end{aligned}
$$

where dBS, dLEW and dTES are the parameters determined for the backscatter (bs), leading-edge width (lew) and trailingedge slope (tes) adjustment variables; $H_{0}$ is the mean altitude; s $x$ and sy are the parameters for adjustment variables $x$ and $y$, i.e. the local slopes; $c x, c y$ and $c x y$ complete the quadratic modelling of the surface (corresponding to curvatures); and $\mathrm{d} h / \mathrm{d} t$ is a linear time trend. The overbar represents the local mean, and $\operatorname{res}(x, y, t)$ are the residuals. ICESat measurements only span $100-200 \mathrm{~m}$ across track, and good results are achieved with slope only. Here a quadratic surface model was used because of the wider scatter of points across-track.

The processing can be broken down into the following steps:

choose a location along-track

select all measurements within a $500 \mathrm{~m}$ radius

fit the ten parameters

compute the standard deviation of residuals

reject individual measurements whose corresponding residuals are larger in absolute value than three times this standard deviation ( $3 \sigma$ editing)

fit the ten parameters only on the remaining measurements if $<130$ measurements are left for the second fit or if the standard deviation of residuals after this second fit is $>5 \mathrm{~m}$, reject the processed point

go to the next location along-track, $1 \mathrm{~km}$ farther and repeat the same process.

In theory, with all passes available, each processed point should be computed from 200 measurements, but this number is reduced because of missing passes and $3 \sigma$ editing. The threshold at 130 measurements was determined empirically from a histogram as we expect that a location with fewer measurements will suffer from measurement quality problems (due to crevasses, very steep slopes, etc.). For the whole AIS, this criterion eliminates $4.8 \%$ of points.

The regularity and density of the temporal sampling allow us to reuse the residuals from the fit to compute surface height acceleration (second derivative with respect to time, $\mathrm{d}^{2} h / \mathrm{d} t^{2}$ ) or to take into account the seasonal signal. To determine the elevation acceleration, we fit the following least-square model:

$$
h(t)=h_{0}+a(t-\bar{t})+b\left(t^{2}-\overline{t^{2}}\right)
$$

where $t$ is the time, $a$ is our estimate of $\mathrm{d} h / \mathrm{d} t, b$ our estimate of $\mathrm{d}^{2} h / \mathrm{d} t^{2}$ and the overbar represents the mean.

In the following, interpolated maps rendered on a $5 \mathrm{~km} \times 5 \mathrm{~km}$ grid are built by averaging with Gaussian weights. All points within a $25 \mathrm{~km}$ radius are taken into account and weighted with a decorrelation radius of $10 \mathrm{~km}$.

The interpolated map of $\mathrm{d} h / \mathrm{d} t$ is given in Figure 1. Ninetyfive per cent of elevation changes are within $15 \mathrm{~cm} \mathrm{a}^{-1}$ of zero. These changes are small in amplitude and have a large spatial extension. Rémy and Parouty (2009) showed (by comparing ERS-2 and Envisat elevation trends) that they could vary depending on the observation period. They are attributed to variations in meteorological forcings. A persistent anomaly in accumulation lasting a few years could account for these changes (Rémy and others, 2002; Helsen and others, 2008).

However, it is recognized that ice thickness in some locations does vary because of changes in ice dynamics (Fig. 1). This happens especially in West Antarctica, with the well-documented acceleration of PIG resulting in dramatic thinning of the glacier. The opposite effect is also clearly visible on the small upstream part of Kamb Ice Stream (former Ice Stream C) seen by Envisat (on the Siple Coast, close to the southern limit of coverage at $81.5^{\circ} \mathrm{S}$ ), which is growing thicker since it stopped flowing, around 1850 (Retzlaff and Bentley, 1993; Jacobel and others, 1996; Anandakrishnan and Alley, 1997).

\subsection{Measurement accuracy}

To validate the accuracy of our measurements, we compare them to those of Scott and others (2009) on PIG. They computed elevation change rates from ICESat data and velocities observed during two austral summer campaigns using GPS receivers at three locations (see Table 1; Fig. 2a).

From the along-track elevation time series obtained as the residuals of the processing described in Section 2.1, we derive elevation measurements to be compared to those of Scott and others (2009). First, we select the four points of our dataset that are closest to the locations given in the Table 1 caption and average them to reduce the noise in the series. Then we fit a second-order polynomial and a sine with a 1 year period to account for elevation change rate, elevation 


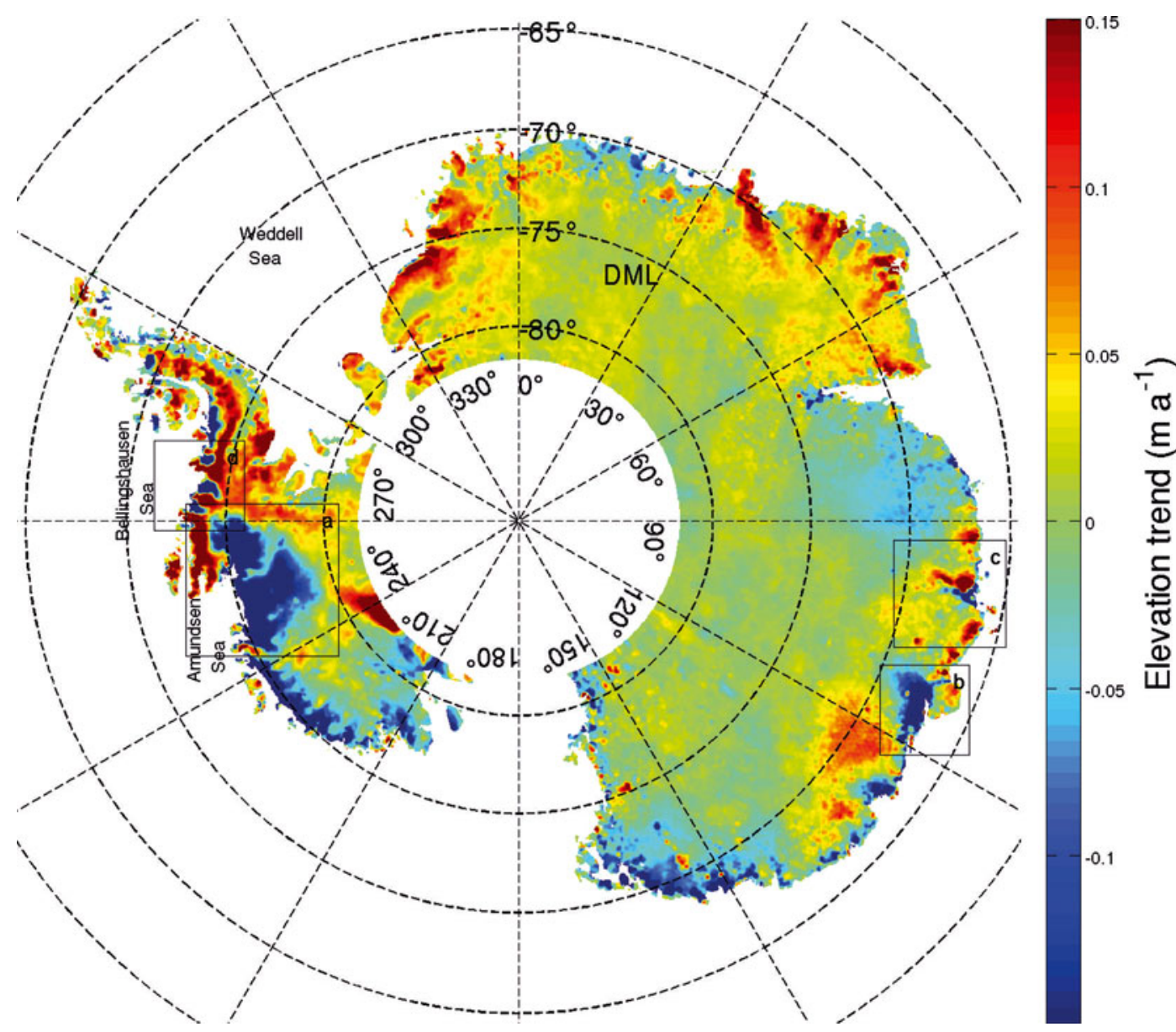

Fig. 1. Map of surface elevation trend, $\mathrm{d} h / \mathrm{d} t$. Boxes delineate areas referred to in subsequent figures. Meridians are plotted in dotted line every $10^{\circ}$ and parallels every $5^{\circ}$. The limit of coverage is at $81.5^{\circ} \mathrm{S}$. DML: Dronning Maud Land.

change acceleration and seasonal variations. Time series and the corresponding fitted curves are given in Figure 3. Values given in Table 1 are computed from the fitted curves over the observation periods used by Scott and others (2009). The error is estimated by propagating uncertainty on the fitted parameters. This error depends on the statistical distribution of measurements and accounts only for the misfit of our fourparameter model to the series.

The only point where the $1 \sigma$ error intervals do not overlap is for the farthest point upslope, $171 \mathrm{~km}$ from the grounding line during the 2007/08 austral summer. Scott and others measured a slowdown in thinning; the elevation trend at PC171 varied from $-1.2 \mathrm{ma}^{-1}$ during GPS1 to $-1.05 \mathrm{~m} \mathrm{a}^{-1}$ during GPS2. There are too few degrees of freedom in our fit to account for this behaviour, as we assume steady elevation acceleration; but the precision of our altimetry data over such short timescales is not sufficient to achieve better results.

The difference in location between the field GPS measurements and the altimeter measurements could contribute a little to the difference. From the spatial gradient of the elevation trend, we estimate that this location error adds $<0.1 \mathrm{~m} \mathrm{a}^{-1}$ if the distance between PC55 and the chosen satellite measurements is $10 \mathrm{~km}$. The error is lower for the other points, respectively 3 and $2 \mathrm{~cm} \mathrm{a}^{-1}$ at PC111 and PC171. These values are added to the error estimates described previously.

Part of the seasonal signal in radar height measurements might come from badly corrected effects of the seasonal

Table 1. Elevation changes $\left(\mathrm{m} \mathrm{a}^{-1}\right)$ at Scott and others' (2009) points, and values estimated by fitting a quadratic dependency on time and a 1 year sine to our Envisat height residuals closest to PC55 $\left(75.357^{\circ} \mathrm{S}, 97.86^{\circ} \mathrm{W}\right), \mathrm{PC} 111\left(75.406^{\circ} \mathrm{S}, 95.88^{\circ} \mathrm{W}\right)$ and $\mathrm{PC} 171\left(75.455^{\circ} \mathrm{S}\right.$, $\left.93.71^{\circ} \mathrm{W}\right)$

\begin{tabular}{lccccc}
\hline & $2003-07$ & \multicolumn{2}{c}{ GPS1 (austral summer 2006/07) } & \multicolumn{2}{c}{ GPS2 (austral summer 2007/08) } \\
Point & $\begin{array}{c}\text { ICESat } \\
\text { (Scott and others, 2009) }\end{array}$ & $\begin{array}{c}\text { Envisat } \\
\text { (this study) }\end{array}$ & $\begin{array}{c}\text { GPS } \\
\text { (Scott and others, 2009) }\end{array}$ & $\begin{array}{c}\text { Envisat } \\
\text { (this study) }\end{array}$ & $\begin{array}{c}\text { GPS } \\
\text { (Scott and others, 2009) } \\
\text { (this study) }\end{array}$ \\
\hline PC55 & $-1.9 \pm 0.4$ & $-2.15 \pm 0.3$ & $-3.5 \pm 0.65$ & $-3.0 \pm 0.5$ & $-3.65 \pm 0.7$ \\
PC111 & $-1 \pm 0.4$ & $-1.2 \pm 0.15$ & $-2.0 \pm 0.4$ & $-2.2 \pm 0.3$ & $-2.8 \pm 0.6$ \\
PC171 & $-0.6 \pm 0.4$ & $-0.7 \pm 0.1$ & $-1.2 \pm 0.2$ & $-1.4 \pm 0.3$ & $-1.05 \pm 0.2$ \\
\hline
\end{tabular}



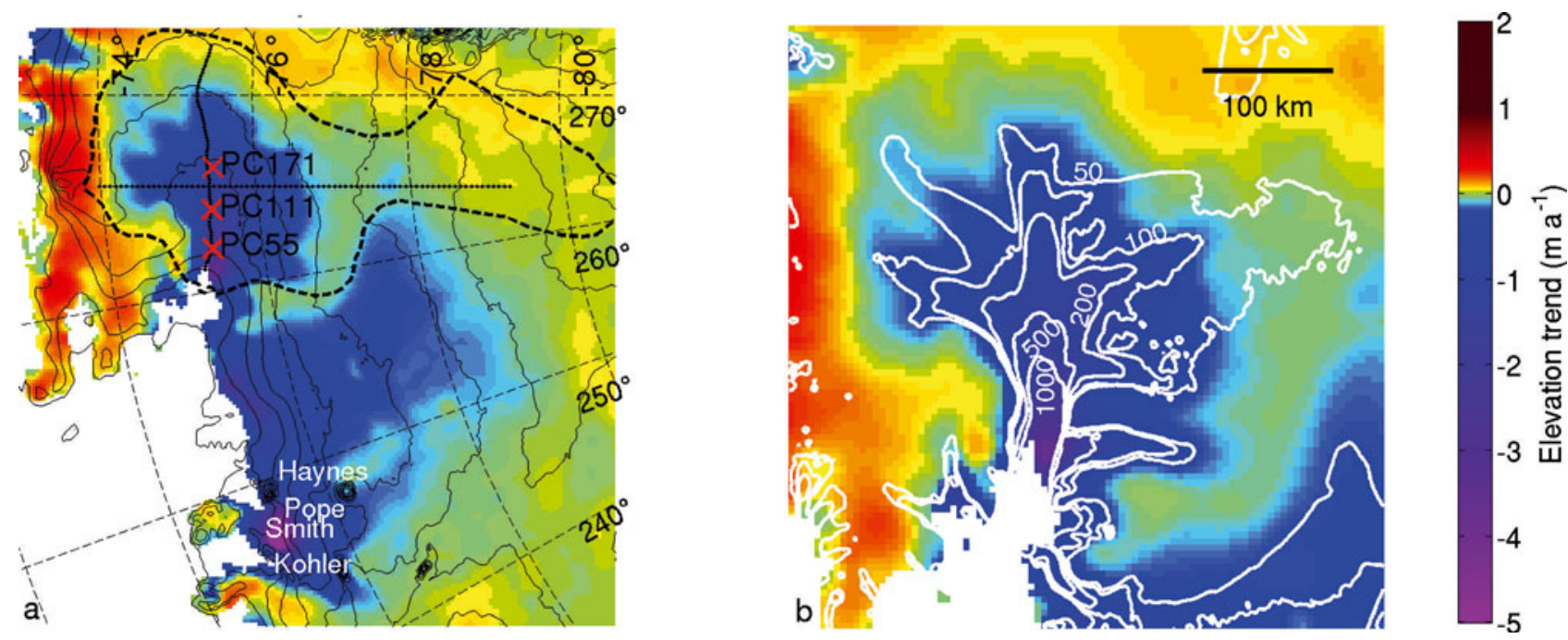

Fig. 2. (a) Enlargement of the Amundsen Sea Embayment (box a in Fig. 1) $\mathrm{d} h / \mathrm{d} t\left(\mathrm{ma}^{-1}\right)$. PIG basin is delineated in dashed black line; grounding line from the Moderate Resolution Imaging Spectrpradiometer (MODIS) Mosaic of Antarctica is in red. Altitude contours every $250 \mathrm{~m}$ are thin black lines. Red crosses show the location of Scott and others' (2009) GPS measurements, and dotted black lines are the profiles (respectively north-south transect and roughly east-west central flowline) used in Figure 6 . Meridians are every $10^{\circ}$, parallels every $2^{\circ}$. (b) Enlargement of PIG elevation trend. White lines are the speed contours from Rignot and others (2011), plotted at 50, 100, 200, 500 and $1000 \mathrm{~m} \mathrm{a}^{-1}$ (right).

modification of the snowpack properties, as we only fit three waveform parameters to account for this effect. The contribution from this error is difficult to estimate. Further investigation is still needed for an independent validation of radar altimeter time series over ice sheets with respect to this phenomenon (Arthern and others, 2001; Rémy and Parouty, 2009). However, the overall good agreement between our values and those of Scott and others (2009) gives good confidence in the quality of our altimetry data.

\subsection{Errors in interpretation induced by interannual variability in accumulation rates}

The natural year-to-year variability of accumulation could produce height changes over the observation period that should not be interpreted as long-term mass imbalance of the ice sheet.

We assume that there is no significant trend in accumulation over recent decades (Monaghan and others, 2006) and that the spatial and temporal variability of accumulation were the same as now. The idea is that the stronger the accumulation, the larger the deviation from steady state could be.

We used a simplistic model to estimate the contribution of the natural variability of accumulation to surface height change. We took into account the contribution of past and recent accumulation anomalies through the variation in firn compaction velocity they induce.

To do this, we drew 3000 values of accumulation with a standard deviation of $30 \%$ around the local mean. Each value produces a height anomaly that evolves with time as the snow is compacted into ice. The firn compaction is simply modelled by a decreasing exponential as in Rémy and Parrenin (2004), where the density of snow evolves as

$$
\rho(t)=\rho_{\mathrm{i}}-\left(\rho_{\mathrm{i}}-\rho_{X}\right) \exp (-k t) .
$$

We ran the simulation 10000 times for a range of accumulation values and for several values of the densification coefficient $k(0.1,0.01$ and 0.001$)$.
From the accumulation map by Arthern and others (2006), we then estimated the potential contribution of accumulation variation to the elevation change on each $5 \mathrm{~km} \times 5 \mathrm{~km}$ pixel on our map.

Although this model is only first-order, it provides a guess of where elevation changes are significantly dominant over natural variability. With this method, it is also possible to estimate the influence of accumulation variability on the second derivative of surface height.

This accumulation contribution is then considered to be an error and is combined with the standard deviation of $\mathrm{d} h / \mathrm{d} t$ and $\mathrm{d}^{2} h / \mathrm{d} t^{2}$ as estimated during the least-square fit. We assume that both errors are weakly linked, so we sum their variances.

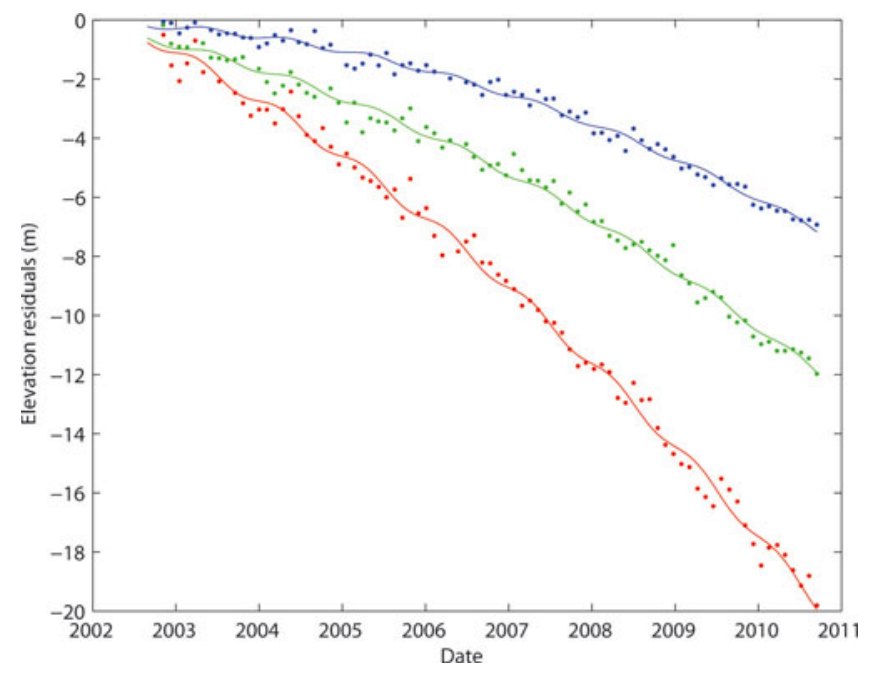

Fig. 3. Averaged surface elevation time series at the three points closest to Scott and others' (2009) GPS location. Red: PC55; green: PC111; blue: PC171 (see Table 1 caption for locations). Each thin line is the result of the least-square fit to the corresponding series. 

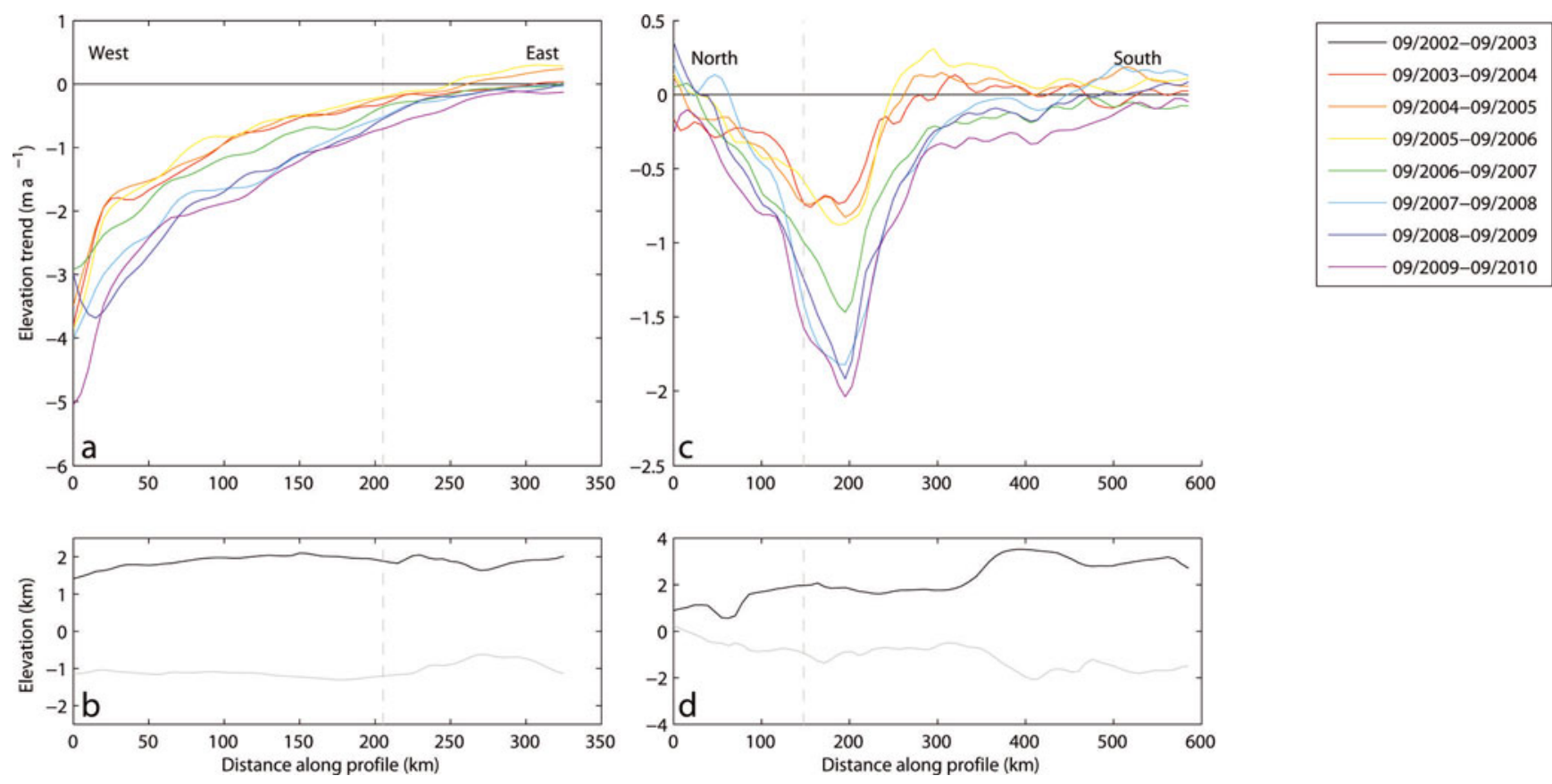

Fig. 4. Elevation trend along the profiles shown in Figure 2a. (a) Along the central flowline, directed west-east, i.e. going upslope from the grounding line, and (c) along the north-south profile. Date format is month/year. Bed elevation (grey line, from Holt and others, 2006) and surface elevation (black line) are shown below $(b, d)$.

\section{PINE ISLAND GLACIER}

On PIG, we observe 'channels' of thinning corresponding to channels of fast flow. Pritchard and others (2009) observed intense dynamic thinning on the fast-flowing trunk (see their fig. 3). Here, thanks to better spatial resolution, we demonstrate that thinning also follows the branches of the flow pattern (Fig. 2b).

In order to better describe the temporal evolution of the whole basin, we plot the evolution with time of elevation rates along two profiles shown in Figure 2a (north-south transect and central flowline). Height measurements are plotted according to the method described at the end of Section 2.1 and re-interpolated along the profiles. We chose to average in time over periods of 1 year from September to September to take all data into account. Both transects (Fig. 4) exhibit increasing thinning, with breaks from September 2005 to September 2006 and September 2007 to September 2008, and the north-south transect also displays an impressive propagation of the thinning towards the south.

In order to compute the volume change with respect to the first full cycle of Envisat radar altimeter observations in October 2002, we integrate the elevation measurements over the whole PIG basin. We observe (Fig. 5) a clear increase of loss since the beginning. Moreover, we observe a break in the volume balance of the glacier around 2006 as the volume loss rate increases from $7 \mathrm{~km}^{3} \mathrm{a}^{-1}$ in the first half of the period to $48 \mathrm{~km}^{3} \mathrm{a}^{-1}$ in the second half. Note that, especially with such a curve, the estimation depends on the fitting. Fitting a parabola would yield a loss of $22 \mathrm{~km}^{3} \mathrm{a}^{-1}$ at the beginning of 2006, but the volume balance would then be slightly positive towards the end of 2002. These values are consistent with estimates by Rignot (2008) who computed a mass loss of $24 \mathrm{Gta}^{-1}$ in 2000 and $46 \mathrm{Gta}^{-1}$ in 2007.

We also observe that the highest part of the PIG basin (i.e. its southern lobe) seems to be thickening, probably due to higher than average accumulation. This thickening shows that accumulation also plays a role in the evolution of surface height in this sector, and firn compaction modelling would be necessary to compute an accurate mass-balance estimate (Helsen and others, 2008). This higher than average accumulation and the consideration of the entire basin, in contrast to former studies (Wingham and others, 2009), might explain why we observe little volume change at the beginning of the series in fall 2002 (Fig. 5).

The cause for the propagation far inland of this perturbation is still a matter of debate. To investigate the propagation, we display in Figure 6 the data shown in Figure 4a in another way, where the residuals are averaged every quarter instead of every year. From this figure, the propagation speed can be estimated as $\sim 30 \mathrm{~km} \mathrm{a}^{-1}$ (a vertical tangent means no propagation, while a horizontal one means instantaneous propagation). The propagation seems to decrease at $\sim 300 \mathrm{~km}$ from the grounding line, where the bed rises to $-500 \mathrm{~m}$. By contrast, it reaches $75 \mathrm{~km} \mathrm{a}^{-1}$ at the beginning of the profile but decreases during the period. The effect of seasonal accumulation is seen as contour undulations.

Joughin and others (2003) and Scott and others (2009) suggested that the propagation is driven by the increase in driving stress. The driving stress $(\tau=\rho g \alpha E$, where $\rho$ is the ice density, $g$ the acceleration of gravity, $\alpha$ the surface slope and $E$ the ice thickness) is proportional to slope and ice thickness, so that, thinning in the lowest part of the glacier being stronger, it increases the surface slope, thus increasing the driving stress:

$$
\frac{\Delta \alpha}{\Delta t}=\frac{\left(\Delta \frac{\mathrm{d} h}{\mathrm{~d} t}\right)}{D},
$$

where $t$ is the time, $D$ is the distance between points where $\mathrm{d} h / \mathrm{d} t$ is estimated, and $\Delta$ is the difference operator. At first order, this effect dominates the overall diminution of ice thickness (e.g. Scott and others, 2009). 


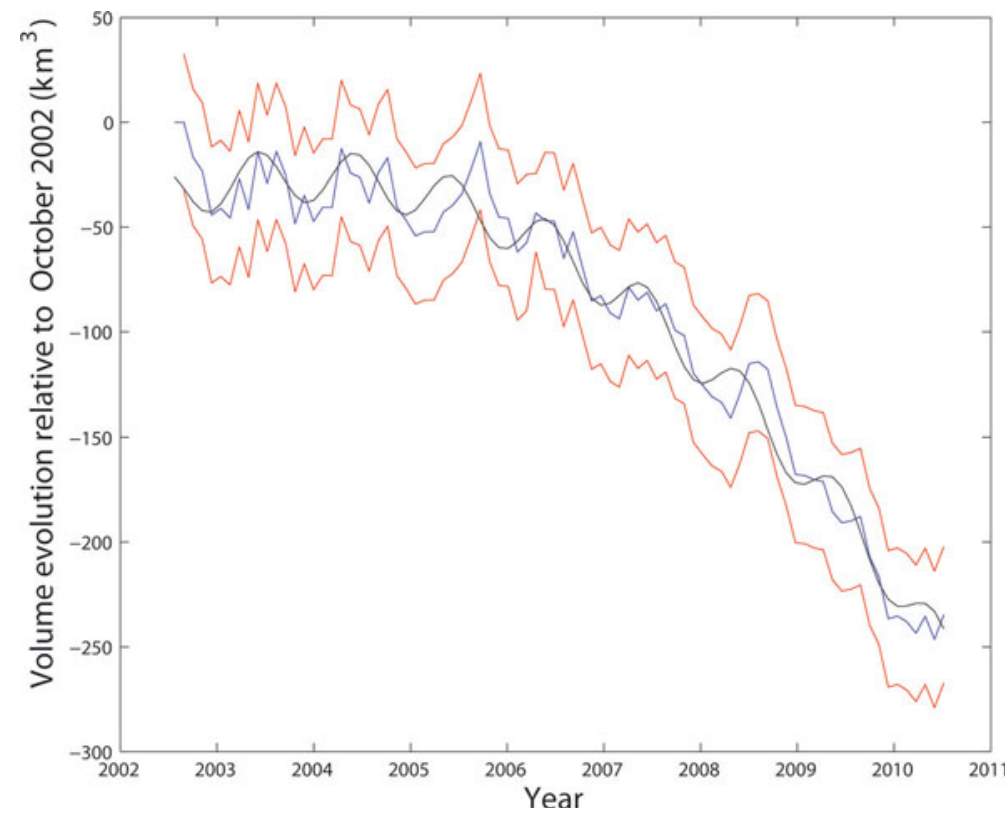

Fig. 5. Volume change of the PIG basin between 2002 and 2010. The blue line is measurements, the black line is a fit of a quadratic dependency with time and a 1 year sine, and the red lines define the $1 \sigma$ error around the blue line.

Scott and others (2009) estimated a slope increase along the centre line of PIG of $\sim 2 \times 10^{-5} \mathrm{a}^{-1}$ between 2006 and 2008. From our estimation of elevation changes, we find the same order of magnitude: $1.5 \times 10^{-5} \mathrm{a}^{-1}$ for the same period. On average, we find $\sim 1.1 \times 10^{-5} \mathrm{a}^{-1}$ over the Envisat period, with a mean slope of $1.5 \times 10^{-3}$ along the centre line. This could mean that the slope change accelerated during these 8 years. Our estimates agree with those of Joughin and others (2003), while, as stated above, values by Scott and others (2009) are larger than ours, probably because of the limited time-span of their austral summer measurements.

Figure 7 shows the evolution of the slope along the centre-line profile shown in Figure 2a, for each half of the period and for the full 8 year period. It is given in per cent of the initial slope, as derived from the topography by Rémy and others (1999). The slope and its evolution are computed by fitting a plane to the surface within a disc with a $20 \mathrm{~km}$ radius. Up to $\mathrm{km} 170$, the increase in driving stress is $\sim 1 \% \mathrm{a}^{-1}$, with peaks up to $1.3 \% \mathrm{a}^{-1}$ during the second half of the period. If we assume the Glen exponent is $n=3$, the increase in speed is thus $3-4.5 \% \mathrm{a}^{-1}$ over this period, which is consistent with the values of Scott and others (2009) (acceleration of 4.8 and $4.1 \% \mathrm{a}^{-1}$ respectively 111 and $171 \mathrm{~km}$ from the grounding line). Farther inland, 200$250 \mathrm{~km}$ from the grounding line, the increase is less but still significant, from $0.3 \% \mathrm{a}^{-1}$ for the period $2002-06$ to $0.6 \% \mathrm{a}^{-1}$ for the period 2006-10, suggesting a recent increase in speed of $1.5 \% \mathrm{a}^{-1}$.

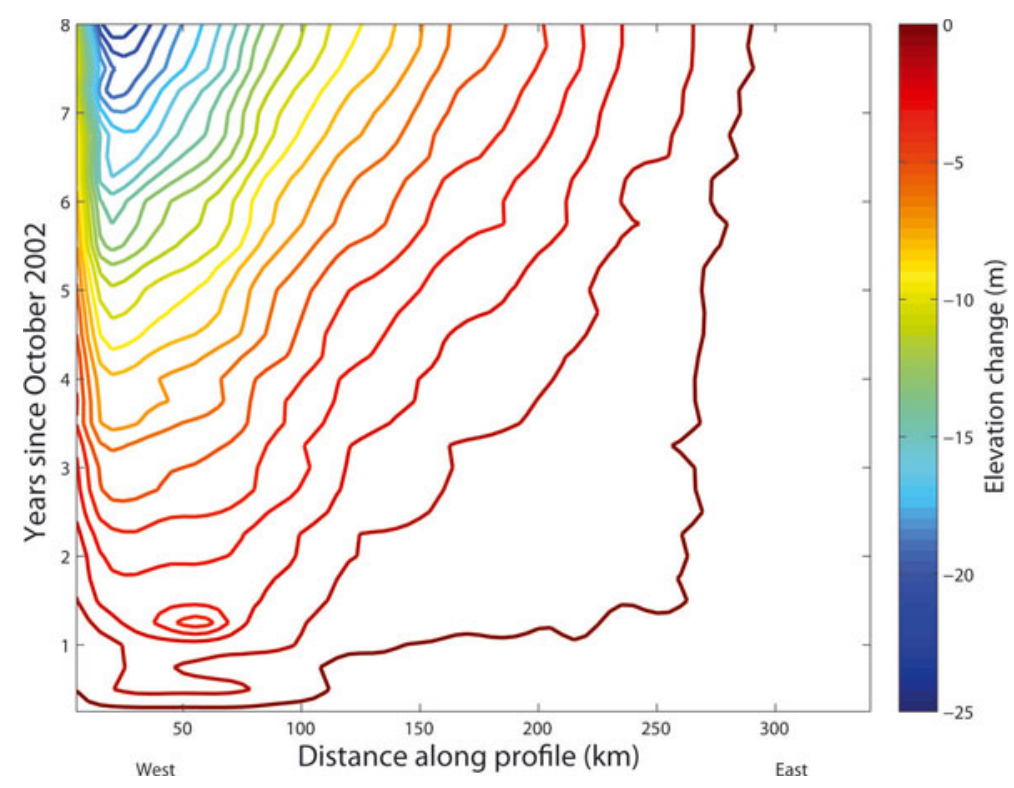

Fig. 6. Contour plot of the evolution of elevation change along the PIG centre line shown in Figure 3. $x$-axis is the distance from the bottom of the profile (on PIG shelf) to the top of the profile; $y$-axis is the time since the beginning of the series. The 'slope' of the contours indicates the speed of propagation of the thinning. 


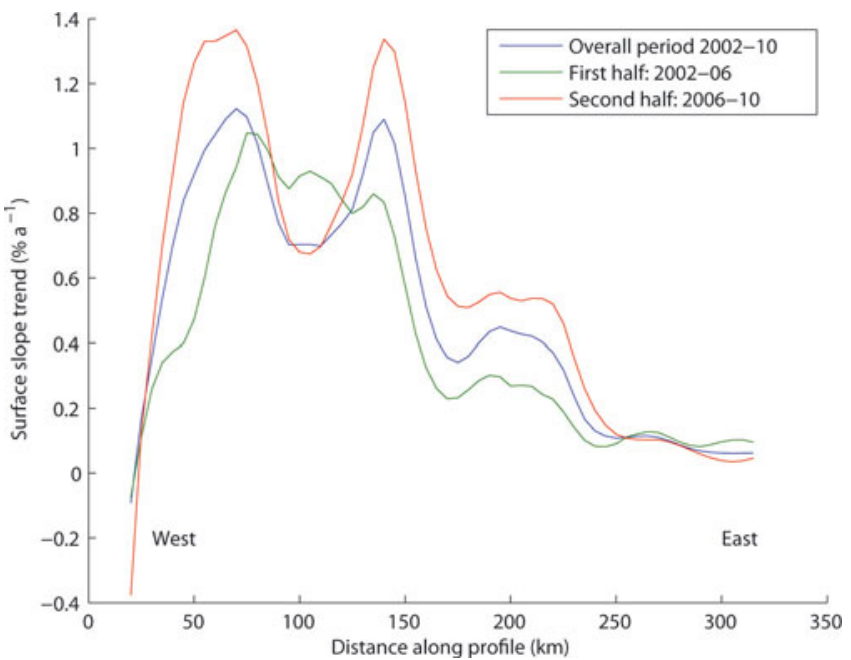

Fig. 7. Surface slope trend $\left(\% \mathrm{a}^{-1}\right)$ of initial slope along PIG centre line.

We computed the second derivative with time of the surface height (elevation acceleration; Fig. 8b) because inspection of the time series reveals an increase in thinning (e.g. Fig. 3). Wingham and others (2009) described an increase in thinning at the PIG grounding line. We extended the area to the whole Amundsen Sea Embayment (ASE) which is examined in the next section, to investigate the hypothesis of a regional phenomenon such as increased iceshelf melting driven by ocean warming (Fig. 2a).

Most of the height loss occurs south of the central flowline (i.e. to the right of this line in the figures). The acceleration map (Fig. 8b) also shows that thinning is propagating southward. To the north, PIG is limited by high subglacial grounds (Jones Mountains) whereas its southern branches reach the thicker centre of the West Antarctic ice sheet (WAIS); ice to the north is $<1000 \mathrm{~m}$ thick while it is $>2000 \mathrm{~m}$ thick to the south (see north-south transect of PIG in Fig. $4 \mathrm{c}$ and $\mathrm{d}$ ). To the east, thinning is detected within a few tens of kilometres of the divide with the Ronne Ice Shelf drainage basin (Fig. 4a and b).

In Figure 4c, we observe that the centre line is not the place with the largest thinning rates. On the north-south transect, the maximum thinning rate is reached $\sim 50 \mathrm{~km}$ farther south (at this latitude, satellite ground tracks are spaced $25 \mathrm{~km}$ apart so we have sufficient resolution to conclude). From our data we infer that the thinning pattern of PIG will spread southwards.

On average, the PIG basin is thinning, and this thinning is accelerating at up to several tens of $\mathrm{cm} \mathrm{a}^{-2}$. To the west of PIG, Thwaites Glacier and glaciers flowing into the Crosson Ice Shelf (Pope, Kohler and Smith glaciers) are also losing height at an accelerating rate, but the phenomenon is located within $100 \mathrm{~km}$ of the coast (Figs $8 \mathrm{~b}$ and $9 \mathrm{~b}$ ).

The regional behaviour of glaciers of the ASE supports the hypothesis that PIG's retreat was triggered by a regional cause. However, it is sustained and propagated by some phenomena specific to PIG (e.g. Joughin and others, 2010).

The map of elevation change acceleration (Fig. 8b) shows that most of the PIG northern basin is undergoing acceleration (in terms of elevation) whereas neighbouring glaciers are only subject to acceleration near the coast and up to $50-100 \mathrm{~km}$ inland.

\section{OTHER GLACIERS}

\subsection{West Antarctic ice sheet}

Most of the coast to the west of PIG exhibits thinning that cannot be attributed to accumulation variation (Figs 8 and 9). In Ellsworth Land (part of the WAIS at the base of the Peninsula), several glaciers also exhibit thinning. These observations are detailed below.

Thwaites Glacier (TG) is a major contributor to WAIS ice discharge, with an outflow estimated at $109 \pm 5 \mathrm{Gta}^{-1}$ in 2007 leading to an imbalance of $-34 \pm 16 \mathrm{Gta}^{-1}$ (Rignot, 2008). The bed under TG is also sloping downward inland (Holt and others, 2006) and, in the future, TG could be subject to changes similar to those of PIG. For the moment,
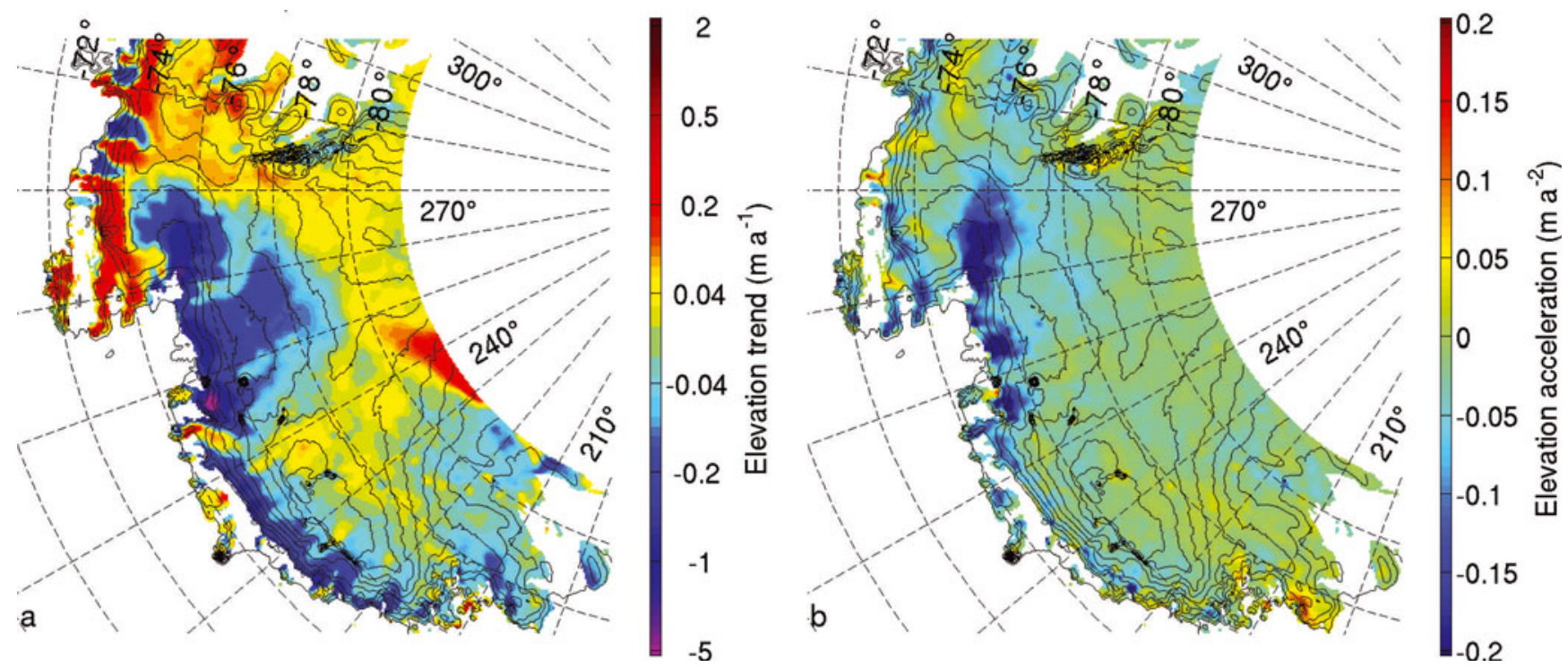

Fig. 8. Rate of elevation (a) and acceleration of elevation change (b) over the WAIS. Thin black lines are altitude contours every $250 \mathrm{~m}$ (from RADARSAT-1 Antarctic MappingProject (RAMP) topography (Liu and others, 2001)). 

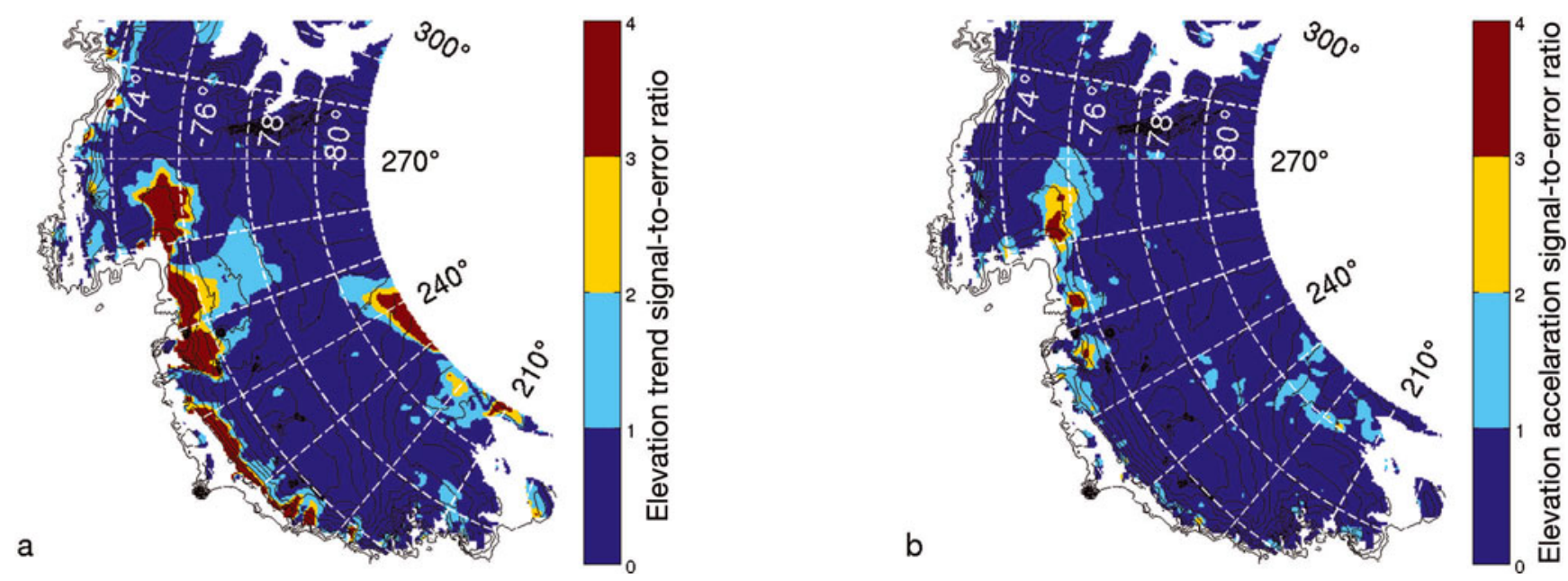

Fig. 9. Maps of the ratio of the absolute value of elevation trend (a) and elevation acceleration (b) to their respective errors.

however, it does not seem to be subject to the same dramatic inland acceleration as PIG.

Thinning on TG is widespread and significant with respect to our error analysis, but less intense than on PIG. From our gridded maps, the largest height variation on TG is $-4.5 \pm 0.7 \mathrm{~m} \mathrm{a}^{-1}$, compared with $-6.2 \pm 1.2 \mathrm{~m} \mathrm{a}^{-1}$ on PIG on average during 2002-10. Errors are derived from the difference between maps built on ascending tracks only and descending tracks only. They reflect the raw altimetric error and the different sampling.

Our acceleration values are too near the uncertainty margins for any interpretation, except for the first $50 \mathrm{~km}$ from the coast, where acceleration is significant within two standard deviations. Rignot (2008) observed a widening of the fast-flowing zone. Near the grounding line we do not process the time series, because surface slope and footprintscale $(2-6 \mathrm{~km})$ roughness induced large errors. This restriction is inherent to radar altimetry and makes measurements sparse and of lesser quality, precluding a spatially accurate interpretation. In other words, we cannot observe the widening reported by Rignot (2008) but this does not mean it has not happened.

Glaciers flowing in the Crosson Ice Shelf are confined between mountain ranges to the south of their small basins (Mount Takahe and Kohler Range), so the strong thinning they undergo cannot propagate far inland. Smith Glacier, in particular, flows in a deep trench (Holt and others, 2006). In contrast to their small basins and small potential contribution to global sea level, these glaciers are losing height at a very fast rate. The largest height variation from our gridded map is $-7.4 \pm 1.6 \mathrm{~m} \mathrm{a}^{-1}$ on average over the Envisat period.

Farther west, glaciers flowing towards the Pacific Ocean (tributaries to the Getz Ice Shelf, Cordell Hull and Emory Land Glaciers) also exhibit dynamic thinning. The Envisat record may be too short along this coast, but no acceleration is observed beyond our uncertainty margins.

In Figure 9a, the map associated with the elevation trend shows that the whole Pacific coast of the WAIS is losing height at a rate that cannot be explained by accumulation fluctuations. The growth of Kamb Ice Stream at the limit of coverage also stands out clearly.

Finally, glaciers along the coast of the Bellingshausen Sea are also thinning, especially those of Eltanin Bay (box $d$ in Fig. 1; Fig. 10). Glaciers flowing in the Abbot Ice Shelf (directly north of PIG) are too small and too near the coast to be correctly observed. From the regional growth of the ice sheet at high altitude $(>1000 \mathrm{~m})$, we infer that the accumulation rate was higher than average in Ellsworth Land (northeastern part of the WAIS). Fast-thinning glaciers (up to $-2.5 \pm 1 \mathrm{~m} \mathrm{a}^{-1}$ ) are thus probably losing mass even faster, as part of the height loss due to ice loss is compensated by snow gain, at lower density.

\subsection{East Antarctic ice sheet (EAIS)}

Totten Glacier (Fig. 11) has the largest outflow in East Antarctica (Rignot, 2002) and is reported to be thinning (Rignot and Thomas, 2002; Zwally and others, 2005; Pritchard and others, 2009). Zwally and others (2005) suggested that this evolution could be driven by the same causes as PIG, i.e. the influence of atmospheric and ocean forcings, and Pritchard and others (2009, supp. fig. S8) emphasized that surrounding glaciers follow the same evolution, reinforcing this hypothesis.

Not many altimetry data points pass the tests for acceptable quality over the last kilometres of Totten Glacier, probably because of the steep and crevassed surface.

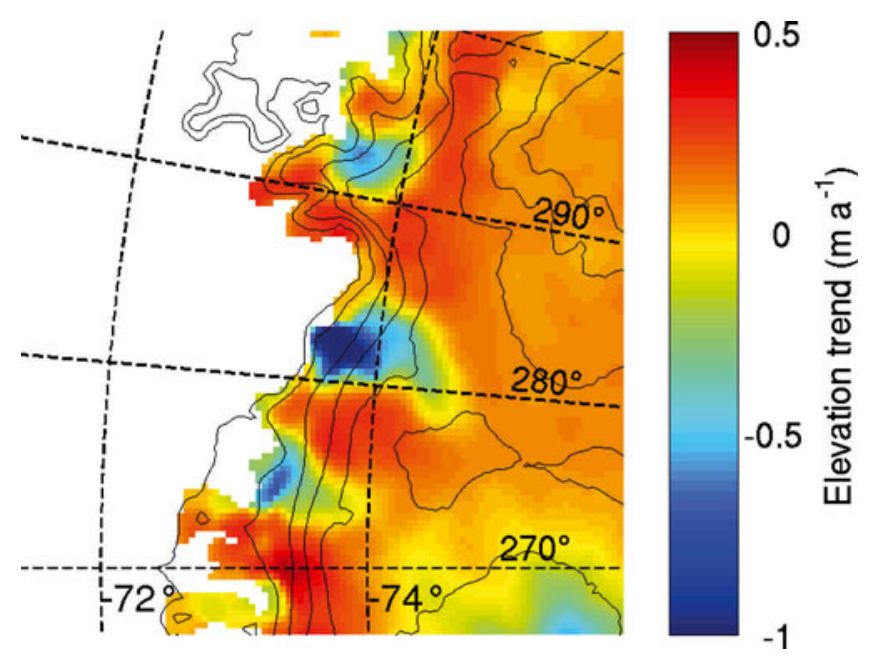

Fig. 10. Enlargement of $\mathrm{d} h / \mathrm{d} t$ maps around Eltanin Bay, WAIS (box d in Fig. 1). Meridians every $5^{\circ}$, parallels every $2^{\circ}$, altitude contours every $250 \mathrm{~m}$. 

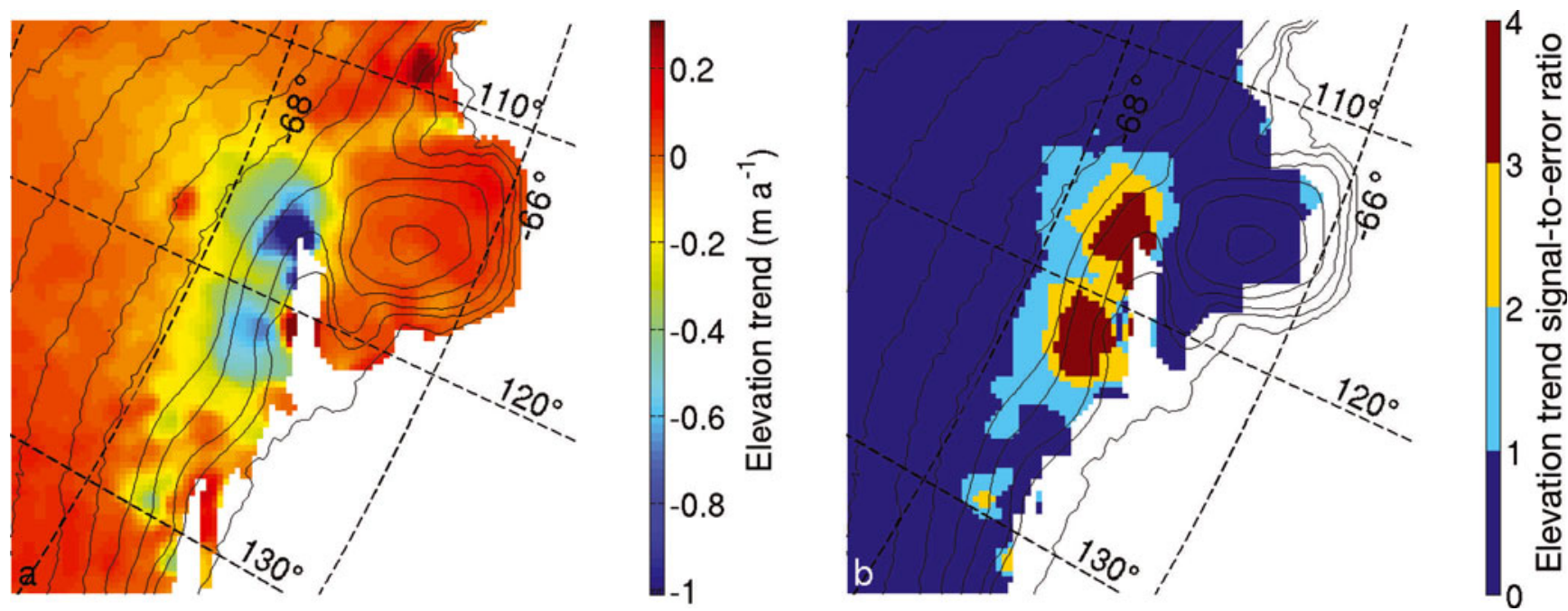

Fig. 11. Enlargement of the $\mathrm{d} h / \mathrm{d} t$ map on Law Dome and Totten Glacier, EAIS, defined by box b in Figure 1. (a) Altitude contours every $250 \mathrm{~m}$. (b) Map of the ratio of the absolute value of elevation trend to the corresponding error.

However, the remaining ones that are closest to the grounding line exhibit negative elevation change (up to $-1.2 \pm 0.6 \mathrm{~m} \mathrm{a}^{-1}$ on average over the period). To reinforce the dynamic argument, a few measurement points are available on the 'ridge' between the main tributary to Totten Glacier (flowing northeastwards from 'behind' Law Dome) and another tributary, slightly to the east, flowing northwards and visible on the Moderate Resolution Imaging Spectroradiometer (MODIS) Mosaic of Antarctica (Scambos and others, 2007). This ridge is also losing height, but much less rapidly than the surrounding fast-flowing areas. Figure 11 shows that variation in accumulation could explain height variation on this ridge but not on the faster-flowing areas. However, we do not observe accelerated thinning, and thus confirm the previous results of Rignot (2006).

Denman Glacier (Fig 12) is located along the Queen Mary Coast and flows into the Shackleton Ice Shelf, between the Amery Ice Shelf to the west and Law Dome to the east. It is bounded by mountains $\sim 1500 \mathrm{~m}$ high and its path is easy to infer from the altitude contours (cf. Rignot, 2002). Despite a relatively rough topography, some points are available on

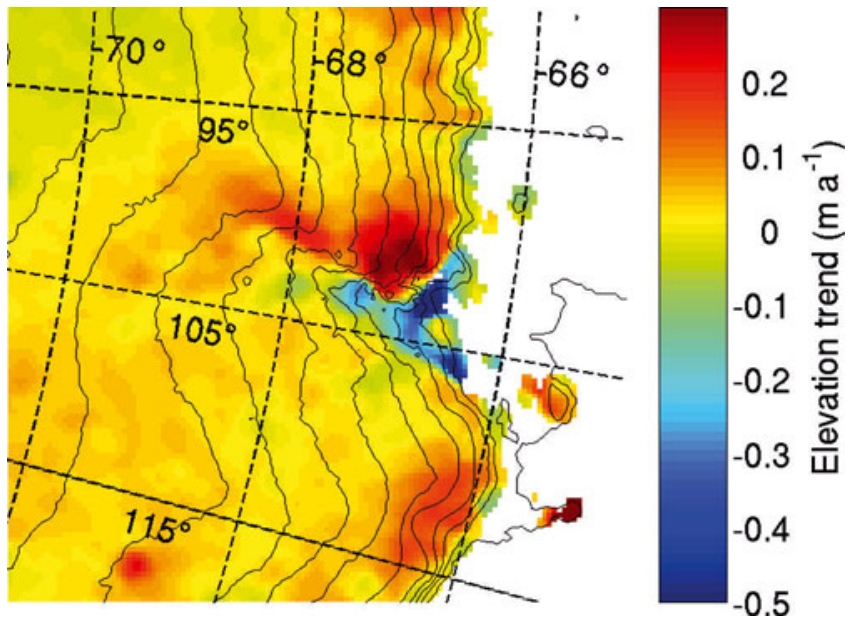

Fig. 12. Enlargement of $\mathrm{d} h / \mathrm{d} t$ maps around Denman Glacier, EAIS (box c in Fig. 1). Meridians every $5^{\circ}$, parallels every $2^{\circ}$, altitude contours every $250 \mathrm{~m}$. the glacier itself. The higher terrain to the west gained height very rapidly over the observation period (up to $\sim 0.35 \mathrm{~m} \mathrm{a}^{-1}$ ), while the trunk of the glacier, in its 'trench', lost height (up to $-0.4 \mathrm{~m} \mathrm{a}^{-1}$ ). The clearly delineated thinning pattern at the bottom of the trench points towards a local meteorological phenomenon such as wind erosion (Scarchilli and others, 2010), or orographic effect on precipitation (Van den Broeke and others, 2006). The altimetric backscatter decreases during the observation period, suggesting a change in snowpack characteristics, but the link between electromagnetic properties and height is not stronger in this region than in other coastal areas. The backscatter trend is $-0.2 \mathrm{~dB} \mathrm{a}^{-1}$ on the fast-flowing part of the glacier, and dependence of height on backscatter is around $-1 \mathrm{~m} \mathrm{~dB}^{-1}$ in the area, which means that our correction adds another $20 \mathrm{~cm} \mathrm{a}^{-1}$ of thinning. The observed signal of $-0.4 \mathrm{~m} \mathrm{a}^{-1}$ (after correction) is likely to reflect a real change in surface height, which is consistent with Pritchard and others (2009).

In Dronning Maud Land (DML), we observe thickening, closely related to the topography (Fig. 1). On the plateau between Dome Fuji and the Weddell Sea, we observe thickening of $2-3 \mathrm{~cm} \mathrm{a}^{-1}$ on average. This zone of growth is delineated by the ridge linking Dome $A$ to Dome Fuji and continuing to the northwest. Other features are linked to the orientation of slopes closer to the northern shore of DML. We reckon that specific meteorological conditions occurred during the observations. Comparing our results with those of Pritchard and others (2009) and former ERS height trends (Rémy and Parouty, 2009), we suggest that the dynamic thickening reported by Pritchard and others (2009) in eastern DML might in fact come from underestimated variability in snowfall.

Finer interpretation of these results would require more information on accumulation variability and compaction. The spatial scales considered here are smaller than in the usual altimetric observations, and some effects such as the orographic forcing of precipitation and local wind erosion might need to be considered.

The error associated with the variability in accumulation close to mountain ranges and sloping terrain is thus probably underestimated from the coarse resolution of the accumulation map we used. 


\section{CONCLUSION}

From a recent and relatively long, homogeneous and dense altimetric time series, we investigated the thinning of several glaciers in the WAIS and EAIS. A formal error analysis and the agreement with previous observations on PIG confirm the reliability of our Envisat-derived elevation changes. Moreover, the along-track analysis provides good space and time sampling, leading to a precise description of the evolution pattern, even of smaller glaciers (e.g. Smith Glacier in the ASE).

First, we confirm that the thinning of PIG is accelerating. This thinning is also spreading to the south of the basin, and the speed of propagation upslope along the centre is $\sim 40 \mathrm{~km} \mathrm{a}^{-1}$. The thinning pattern is well correlated with the flow speed pattern derived from interferometric synthetic aperture radar (InSAR) (Rignot and others, 2011), and thinning is detected $>250 \mathrm{~km}$ from the grounding line.

From the Envisat altimeter dataset we demonstrate that the whole Pacific coast of the WAIS is dynamically thinning. TG is losing up to $4.5 \mathrm{~m} \mathrm{a}^{-1}$, and glaciers of the Crosson Ice Shelf up to $7.5 \mathrm{~m} \mathrm{a}^{-1}$. To the west of PIG, glaciers of the Bellingshausen Sea are also losing height. Acceleration is observed in the coastal region of all glaciers of the Amundsen Sea, and TG in particular should be given attention in the future.

In East Antarctica, we observe thinning on glaciers such as Totten Glacier (up to $1.2 \mathrm{~m} \mathrm{a}^{-1}$ ), but we did not detect significant acceleration of their surface lowering during 2002-10.

The 8 year time series is still too short to compensate statistically for the interannual variation in accumulation, so changes in snow and firn thickness due to specific meteorological conditions dominate the elevation trend and could mask the signal from small dynamic changes in ice thickness. Further studies will extend this analysis to the complete 35 day repeat orbit of previous altimeters (mainly ERS-2 and Envisat). This will provide 15 years of uninterrupted data, doubling the length of the current time series, and will greatly help to reduce uncertainties, smoothing the effect of accumulation variability on the surface height.

\section{ACKNOWLEDGEMENTS}

We thank F. Blarel for preprocessing the data, and E. Berthier for insightful comments. This work was supported by the ADAGe project (ANR-09-SYSC-001) funded by the Agence National de la Recherche (ANR) and by the French Space Agency (CNES) through the TOSCA programme. T. Flament acknowledges a PhD fellowship from CNES and the French National Research Centre (CNRS). Comments from two anonymous referees greatly improved the paper.

\section{REFERENCES}

Allison I, Alley RB, Fricker HA, Thomas RH and Warner RC (2009) Ice sheet mass balance and sea level. Antarct. Sci., 21(5), 413-426 (doi: 10.1017/S0954102009990137)

Anandakrishnan S and Alley RB (1997) Stagnation of Ice Stream C, West Antarctica by water piracy. Geophys. Res. Lett., 24(3), 265-268 (doi: 10.1029/96GL04016)

Arthern RJ, Wingham DJ and Ridout AL (2001) Controls on ERS altimeter measurements over ice sheets: footprint-scale topography, backscatter fluctuations, and the dependence of microwave penetration depth upon satellite orientation. J. Geophys. Res., 106(D24), 33 471-33 484 (doi: 10.1029/2001JD000498)
Arthern RJ, Winebrenner DP and Vaughan DG (2006) Antarctic snow accumulation mapped using polarization of $4.3 \mathrm{~cm}$ wavelength microwave emission. J. Geophys. Res., 111(D6), D06107 (doi: 10.1029/2004JD005667)

Corr HFJ, Doake CSM, Jenkins A and Vaughan DG (2001) Investigations of an 'ice plain' in the mouth of Pine Island Glacier, Antarctica. J. Glaciol., 47(156), 51-57 (doi: 10.3189/ 172756501781832395)

Helsen MM and 7 others (2008) Elevation changes in Antarctica mainly determined by accumulation variability. Science, 320(5883), 1626-1629 (doi: 10.1126/science.1153894)

Holt JW and 8 others (2006) New boundary conditions for the West Antarctic Ice Sheet: subglacial topography of the Thwaites and Smith glacier catchments. Geophys. Res. Lett., 33(9), L09502 (doi: 10.1029/2005GL025561)

Howat IM, Smith BE, Joughin I and Scambos TA (2008) Rates of southeast Greenland ice volume loss from combined ICESat and ASTER observations. Geophys. Res. Lett., 35(17), L17505 (doi: 10.1029/2008GL034496)

Jacobel RW, Scambos TA, Raymond CF and Gades AM (1996) Changes in the configuration of ice stream flow from the West Antarctic Ice Sheet. J. Geophys. Res., 101(B3), 5499-5504 (doi: 10.1029/95JB03735)

Jenkins A and 6 others (2010) Observations beneath Pine Island Glacier in West Antarctica and implications for its retreat. Nature Geosci., 3(7), 468-472 (doi: 10.1038/ngeo890)

Joughin I, Rignot E, Rosanova CE, Lucchitta BK and Bohlander J (2003) Timing of recent accelerations of Pine Island Glacier, Antarctica. Geophys. Res. Lett., 30(13), 1706 (doi: 10.1029/ 2003GL017609)

Joughin I, Smith BE and Holland DM (2010) Sensitivity of 21st century sea level to ocean-induced thinning of Pine Island Glacier, Antarctica. Geophys. Res. Lett., 37(20), L20502 (doi: 10.1029/2010GL044819)

Legrésy B, Papa F, Rémy F, Vinay G, Van den Bosch M and Zanife O-Z (2005) ENVISAT radar altimeter measurements over continental surfaces and ice caps using the ICE-2 retracking algorithm. Remote Sens. Environ., 95(2), 150-163 (doi: 10.1016/j.rse.2004.11.018)

Legrésy B, Rémy F and Blarel F (2006) Along track repeat altimetry for ice sheets and continental surface studies. In Proceedings of the Symposium on 15 Years of Progress in Radar Altimetry, 13-18 March 2006, Venice, Italy. European Space Agency, Noordwijk (ESA SP 614) http://earth.esa.int/workshops/ venice06/participants/181/paper_181_legrsy.pdf

Liu H, Jezek K, Li B and Zhao Z (2001) Radarsat Antarctic mapping project digital elevation model Version 2. National Snow and Ice Data Center, Boulder, CO. Digital media: http://nsidc.org/ data/nsidc-0082.html

Monaghan AJ and 15 others (2006) Insignificant change in Antarctic snowfall since the International Geophysical Year. Science, 313(5788), 827-831 (doi: 10.1126/science.1128243)

Pritchard HD, Arthern RJ, Vaughan DG and Edwards LA (2009) Extensive dynamic thinning on the margins of the Greenland and Antarctic ice sheets. Nature, 461(7266), 971-975 (doi: 10.1038/nature08471)

Rémy F and Parrenin F (2004) Snow accumulation variability and random walk: how to interpret changes of surface elevation in Antarctica. Earth Planet. Sci. Lett., 227(3-4), 273-280 (doi: 10.1016/j.epsl.2004.09.003)

Rémy F and Parouty S (2009) Antarctic ice sheet and radar altimetry: a review. Remote Sens., 1(4), 1212-1239 (doi: 10.3390/rs1041212)

Rémy F, Shaeffer P and Legrésy B (1999) Ice flow physical processes derived from ERS-1 high-resolution map of Antarctica and Greenland ice sheet. Geophys. J. Int., 139(3), 645-656 (doi: 10.1046/j.1365-246x.1999.00964.x)

Rémy F, Testut L and Legrésy B (2002) Random fluctuations of snow accumulation over Antarctica and their relation to sea level change. Climate Dyn., 19(3-4), 267-276 (doi: 10.1007/s00382002-0226-z) 
Retzlaff R and Bentley CR (1993) Timing of stagnation of Ice Stream C, West Antarctica, from short-pulse radar studies of buried surface crevasses. J. Glaciol., 39(133), 553-561

Rignot E (2002) Mass balance of East Antarctic glaciers and ice shelves from satellite data. Ann. Glaciol., 34, 217-227 (doi: 10.3189/172756402781817419)

Rignot E (2006) Changes in ice dynamics and mass balance of the Antarctic ice sheet. Philos. Trans. R. Soc. London, Ser. A, 364(1844), 1637-1655 (doi: 10.1098/rsta.2006.1793)

Rignot E (2008) Changes in West Antarctic ice stream dynamics observed with ALOS PALSAR data. Geophys. Res. Lett., 35(12), L12505 (doi: 10.1029/2008GL033365)

Rignot E and Thomas RH (2002) Mass balance of polar ice sheets. Science, 297(5586), 1502-1506 (doi: 10.1126/science. 1073888)

Rignot E and 11 others (2004) Improved estimation of the mass balance of the glaciers draining into the Amundsen Sea sector of West Antarctica from the CECS/NASA 2002 campaign. Ann. Glaciol., 39, 231-237 (doi: 10.3189/172756404781813916)

Rignot E, Mouginot J and Scheuchl B (2011) Ice flow of the Antarctic Ice Sheet. Science, 333(6048), 1427-1430 (doi: 10.1126/science.1208336)

Scambos TA, Haran TM, Fahnestock MA, Painter TH and Bohlander J (2007) MODIS-based Mosaic of Antarctica (MOA) data sets: continent-wide surface morphology and snow grain size. Remote Sens. Environ., 111(2-3), 242-257 (doi: 10.1016/ j.rse.2006.12.020)

Scarchilli C, Frezzotti M, Grigioni P, De Silvestri L, Agnoletto L and Dolci S (2010) Extraordinary blowing snow transport events in East Antarctica. Climate Dyn., 34(7-8), 1195-1206 (doi: 10.1007/s00382-009-0601-0)

Scott JBT, Gudmundsson GH, Smith AM, Bingham RG, Pritchard HD and Vaughan DG (2009) Increased rate of acceleration on Pine Island Glacier strongly coupled to changes in gravitational driving stress. Cryosphere, 3(1), 125-131 (doi: 10.5194/tc-3-125-2009)
Shepherd A, Wingham DJ, Mansley JAD and Corr HFJ (2001) Inland thinning of Pine Island Glacier, West Antarctica. Science, 291(5505), 862-864 (doi: 10.1126/science.291.5505.862)

Shuman CA, Berthier E and Scambos TA (2011) 2001-2009 elevation and mass losses in the Larsen A and B embayments, Antarctic Peninsula. J. Glaciol., 57(204), 737-754 (doi: 10.3189/002214311797409811)

Smith BE, Fricker HA, Joughin IR and Tulaczyk S (2009) An inventory of active subglacial lakes in Antarctica detected by ICESat (2003-2008). J. Glaciol., 55(192), 573-595 (doi: $10.3189 / 002214309789470879)$

Sørensen LS and 7 others (2011) Mass balance of the Greenland ice sheet (2003-2008) from ICESat data - the impact of interpolation, sampling and firn density. Cryosphere, 5(1), 173-186 (doi: 10.5194/tc-5-173-2011)

Thomas RH, Rignot EJ, Kanagaratnam K, Krabill WB and Casassa C (2004) Force-perturbation analysis of Pine Island Glacier, Antarctica, suggests cause for recent acceleration. Ann. Glaciol., 39, 133-138 (doi: 10.3189/172756404781814429)

Van den Broeke M, Van de Berg WJ and Van Meijgaard E (2006) Snowfall in coastal West Antarctica much greater than previously assumed. Geophys. Res. Lett., 33(2), L02505 (doi: 10.1029/2005GL025239

Wingham DJ, Wallis DW and Shepherd A (2009) Spatial and temporal evolution of Pine Island Glacier thinning, 19952006. Geophys. Res. Lett., 36(17), L17501 (doi: 10.1029/ 2009GL039126)

Zwally HJ and 7 others (2005) Mass changes of the Greenland and Antarctic ice sheets and shelves and contributions to sea-level rise: 1992-2002. J. Glaciol., 51(175), 509-527 (doi: 10.3189/ 172756505781829007)

Zwally HJ and 11 others (2011) Greenland ice sheet mass balance: distribution of increased mass loss with climate warming; 2003-07 versus 1992-2002. J. Glaciol., 57(201), 88-102 (doi: $10.3189 / 002214311795306682)$ 